Research Article

\title{
Research on the Large Deformation Prediction Model and Supporting Measures of Soft Rock Tunnel
}

\author{
Junying Rao, Yonghu Tao $\mathbb{D}^{\mathrm{D}}$, Peng Xiong, Chongxin Nie, Hao Peng, \\ Yanghao Xue, and Zuowei Xi
}

School of Civil Engineering, Guizhou University, Guiyang, Guizhou 550025, China

Correspondence should be addressed to Yonghu Tao; 1562521808@qq.com

Received 9 November 2020; Revised 26 November 2020; Accepted 5 December 2020; Published 22 December 2020

Academic Editor: Mingfeng Lei

Copyright ( $\odot 2020$ Junying Rao et al. This is an open access article distributed under the Creative Commons Attribution License, which permits unrestricted use, distribution, and reproduction in any medium, provided the original work is properly cited.

\begin{abstract}
The weak surrounding rock has the characteristics of easy softening, poor integrity, low mechanical strength, etc., which makes it easy to induce different degrees of deformation and damage under excavation disturbance and then seriously affects the stability of the tunnel. Carrying out soft rock tunnel deformation prediction research and designing the supporting structure according to the predicted value is of great significance to engineering construction and design. Based on the grey theory, the large deformation of the vault, shoulder, and waist of the soft rock tunnel are predicted, and then the specific bolt support is designed in the maximum predicted value $\left(S_{\max \cdot R}\right)$ area. The control effects of different bolts, spacing $(d)$, length $(L)$ on the maximum displacement $\left(S_{\max \cdot M}\right)$, and maximum stress $\left(\sigma_{\max M}\right)$ the surrounding rock are analyzed by numerical simulation. Results show that the gray model has high prediction accuracy, the best prediction time is one week, and the maximum error is only 2.99\%; with the decrease in $d$, resin bolt support has a significant supporting effect compared with mortar bolt support, with $S_{\max . M}$ and $\sigma_{\max \cdot M}$ reduced by $64.38 \%$ and $10.35 \%$, respectively; as the $L$ of bolt increases, compared with the mortar bolt support, the resin bolt support has a more obvious restraining effect on the surrounding rock deformation, and $S_{\max \cdot M}$ and $\sigma_{\max \cdot M}$ are reduced by $28.20 \%$ and $10.00 \%$, respectively; when $4.5 \mathrm{~m}<L<6.0 \mathrm{~m}$ and $0.6 \mathrm{~m}<d<0.7 \mathrm{~m}$, resin bolt support should be adopted; in other ranges, mortar bolt support or resin bolt support has a less significant difference in controlling surrounding rock deformation.
\end{abstract}

\section{Introduction}

Large deformation of soft rock tunnels is a common disease in the tunnel field, which not only affects the safety of tunnel construction but also endangers its service life. For engineering, it is crucially important to predict deformation and propose countermeasures. At present, the study of tunnel deformation prediction methods has been mentioned in many documents $[1,2]$, but gray theory is applied to deformation prediction and few studies on the design of support at the maximum deformation [3-5]. Therefore, it is still necessary to research whether the gray theory prediction method is carried out in-depth.

In terms of gray theory and the feasibility study of bolting and shotcrete supports, many scholars at home and abroad have elaborated on it in many aspects; researches such as Szpak and Tchórzewska-Cieślak found that the gray theory was widely used in domestic water, infrastructure construction, economic development, etc. [6-8]; Lu believed that the gray theory could predict mine water inflow with high reliability and applicability [9]; Harding et al. found that bolt support could effectively control surrounding rock deformation, and its support effect was related to bolt parameters [10-12]; Forrestde and Liu convinced that the gray theory prediction could grasp real-time problems in tunnel deformation, slope collapse, and surface settlement [13]; Zhou believed that the gray theory could predict the stress change and unknown deformation of tunnel lining [14]; Huo et al. believed that the gray prediction was an effective means of predicting tunnel deformation, which could be used as a theoretical support for tunnel construction, design, and support to improve operation efficiency [15-18].

Scholars have made many discussions on the research of gray prediction accuracy. Chen et al. believed that the gray 
prediction model could monitor the deformation characteristics of the surrounding rock of the tunnel entrance in real time, the difference between the predicted value and the monitored value was small, and the accuracy was higher $[19,20] ; \mathrm{Hu}$ et al. believed that the gray model predicted tunnel deformation more accurately [21-23]; Ning, Li, and others believed that the use of gray prediction model to monitor large tunnel deformation has high prediction accuracy and small absolute error [24].

In the combined application of the gray theory and numerical simulation, industry experts have carried out many studies; Pan et al. found that the combination of gray theory and numerical simulation can effectively evaluate the deformation of foundation pit excavation and can make real-time prediction [25, 26]; Zhang found that the accuracy of numerical simulation was related to the continuity of the gray sequence [27]; Bi et al. found that the application of gray prediction and simulation technology could effectively improve model accuracy [28]; Hu et al. believed that finite element software analysis of tunnel surrounding rock deformation, combined with gray theory prediction and its mechanical behavior, could effectively change the modeling conditions and accuracy $[29,30]$.

In summary, it was found that the gray prediction model could solve many problems in engineering fields, and its prediction accuracy was higher, which could provide an important reference for the safe construction of the project. However, in their research studies, scholars mainly considered the engineering application of the gray prediction model and analyzing its error between the prediction value and the monitoring value, there was little research on the combination of the prediction model and support design. Therefore, in order to well grasp the tunnel deformation and design support in real time, this article relies on the tunnel of Tong Province, establishes a prediction model based on the gray principle, uses related programming software to draw its prediction curve, and analyzes the rationality of the prediction results. The design support of the dangerous point $\left(S_{\max \cdot R}\right)$ is selected, the maximum displacement $\left(S_{\max }\right)$ and the maximum stress $\left(\sigma_{\max }\right)$ of the surrounding rock under the support conditions are calculated by numerical simulation, and the optimal support proposal is finally given.

\section{Establishment of Gray Forecasting Model}

The tunnel deformation monitoring data generally have no regularity, after the probability and statistics analysis; the gray theory can be used to generate the sequence number with time as the axis to construct the prediction model such as constructing the original sequence number of time $[31,32]$ :

$$
\left\{k^{(0)}\right\}=\left\{k^{(0)}(1), k^{(0)}(2), \ldots, k^{(0)}(b-1), k^{(0)}(b)\right\} .
$$

In equation $(1), k^{(0)}(j)$ is the $j^{\text {th }}$ original sequence number corresponding to the sequence number $j$.

In order to make the data of equation (1) into a regular sequence, the data are accumulated and processed to obtain the following:

$$
k^{(1)}(m)=\sum_{b=1}^{m} k^{(0)}(b)
$$

In equation $(2), k^{(1)}(j)$ is the $j^{\text {th }}$ time new sequence number generated by the accumulation of $j$ original sequence numbers.

Construct a new time series number as follows:

$$
\left\{k^{(1)}\right\}=\left\{k^{(1)}(1), k^{(1)}(2), \ldots, k^{(1)}(b-1), k^{(1)}(b)\right\} .
$$

Thus, the original sequence and the new sequence of tunnel deformation monitoring values can be obtained as follows:

$$
\left\{\begin{array}{l}
\left\{S^{(0)}\right\}=\left\{S^{(0)}(1), S^{(0)}(2), \ldots, S^{(0)}(b-1), S^{(0)}(b)\right\} \\
\left\{S^{(1)}\right\}=\left\{S^{(1)}(1), S^{(1)}(2), \ldots, S^{(1)}(b-1), S^{(1)}(b)\right\}
\end{array}\right.
$$

In equation $(4), F^{(0)} \cdot(j)$ is the $j^{\text {th }}$ original tunnel deformation monitoring value sequence number corresponding to the sequence number $j$ and $F^{(1)} \cdot(j)$ is the new sequence number generated by the accumulation of $j$ original sequence numbers.

Knowing from the gray principle, equation (4) obeys the exponential distribution, constructing a linear differential equation between the monitoring value $S$ and the time $K$, and integrates it to obtain the following.

Differential equation:

$$
\frac{\mathrm{d} S}{\mathrm{~d} k}+R S=H .
$$

Integrating both sides of equation (5), we get

$$
S(k)=C \cdot \operatorname{EXP}(R-R k)+H R^{-1} .
$$

In equation (6), $R$ and $H$ are gray parameters and $C$ is the integral constant.

When $k=1, S(K)=S(1)$; substituting it into equation (6), we get the following equation:

$$
C=S(1)-H R^{-1} \text {. }
$$

Substituting equation (7) into equation (6), the differential equation of $S$ and $K$ can be obtained as

$$
S(K)=\left(S(1)-H R^{-1}\right) \cdot \operatorname{EXP}(R-R k)+H R^{-1} .
$$

According to the definition of the derivative of the function, we get

$$
\left\{\begin{array}{l}
\frac{\mathrm{d} S}{\mathrm{~d} k}=\lim _{\Delta k \longrightarrow 0} \frac{S(k+\Delta k)-S(k)}{\Delta k}, \\
\frac{\mathrm{d} S}{\mathrm{~d} k}=\lim _{\Delta k \longrightarrow 1} \frac{S(k+\Delta k)-S(k)}{\Delta k} .
\end{array}\right.
$$

Knowing from the function continuity, when $\Delta k$ is smaller, the fluctuation of the function value is small. In order to reasonably represent the deformation monitoring value, replacing $S$ with the average value of $S(k)$ and $S$ 
$(k+1)$, and substituting the average value into equation (6), we get

$$
S^{(0)}(k+1)=H-0.5 R\left[S^{(1)}(k)+S^{(1)}(k+1)\right] .
$$

Based on the above derivations, substituting $k=1,2, \ldots$, $b-1, b$ in equation (10), we get

$$
\left\{\begin{array}{l}
S^{(0)}(2)=H-0.5 R\left[S^{(1)}(1)+S^{(1)}(2)\right], \\
S^{(0)}(3)=H-0.5 R\left[S^{(1)}(2)+S^{(1)}(3)\right], \\
\vdots \\
S^{(0)}(b-1)=H-0.5 R\left[S^{(1)}(b-2)+S^{(1)}(b-1)\right], \\
S^{(0)}(b)=H-0.5 R\left[S^{(1)}(b-1)+S^{(1)}(b)\right] .
\end{array}\right.
$$

To solve equation (11), it can be written in matrix form as follows:

$$
\left[\begin{array}{c}
S^{(0)}(2) \\
S^{(0)}(3) \\
\vdots \\
S^{(0)}(b-1) \\
S^{(0)}(b)
\end{array}\right]=\left[\begin{array}{c}
H-0.5 R\left[S^{(1)}(1)+S^{(1)}(2)\right] \\
H-0.5 R\left[S^{(1)}(2)+S^{(1)}(3)\right] \\
\vdots \\
H-0.5 R\left[S^{(1)}(b-2)+S^{(1)}(b-1)\right] \\
H-0.5 R\left[S^{(1)}(b-1)+S^{(1)}(b)\right]
\end{array}\right]
$$

Simplifying equation (12), it can be obtained as follows:

$$
\left[\begin{array}{c}
S^{(0)}(2) \\
S^{(0)}(3) \\
\vdots \\
S^{(0)}(b-1) \\
S^{(0)}(b)
\end{array}\right]=H-0.5 R\left[\begin{array}{c}
\left(S^{(1)}(1)+S^{(1)}(2)\right) \\
\left(F^{(1)}(2)+S^{(1)}(3)\right) \\
\vdots \\
\left(S^{(1)}(b-2)+S^{(1)}(b-1)\right) \\
\left(S^{(1)}(b-1)+S^{(1)}(b)\right)
\end{array}\right]
$$

Making

$$
\begin{aligned}
S * & =\left[\begin{array}{cc}
1 & -\frac{1}{2}\left(S^{(1)}(1)+S^{(1)}(2)\right) \\
1 & -\frac{1}{2}\left(S^{(1)}(2)+S^{(1)}(3)\right) \\
\vdots & \vdots \\
1 & -\frac{1}{2}\left(S^{(1)}(b-2)+S^{(1)}(b-1)\right) \\
1 & -\frac{1}{2}\left(S^{(1)}(b-1)+S^{(1)}(b)\right)
\end{array}\right], \\
S= & {\left[\begin{array}{c}
S^{(0)}(2) \\
S^{(0)}(3) \\
\vdots \\
S^{(0)}(a-1) \\
S^{(0)}(a)
\end{array}\right] } \\
N= & {\left[\begin{array}{c}
H \\
R
\end{array}\right], }
\end{aligned}
$$

equation (13) can be written as

$$
S=S * \times N
$$

From equation (15), we get

$$
N=(S *)^{-1} S .
$$

Equation (16) is expressed by the least square method as follows:

$$
N=\left[\begin{array}{ll}
H & R
\end{array}\right]^{T}=\left((S *)^{T} \cdot(S *)\right)^{-1}(S *)^{T} S .
$$

Equation (17) is the calculation formula of gray parameters.

Summarizing equations (8)-(17), the prediction model of large deformation of soft rock in a tunnel can be obtained as follows:

$$
\begin{aligned}
\widehat{S}^{(1)}(j+1)= & \left(S^{(0)}(1)-H R^{-1}\right) \cdot \operatorname{EXP} \\
& {\left[-R\left(k^{(1)}(j+1)-k^{(1)}(1)\right)\right]+H R^{-1} . }
\end{aligned}
$$

In equation (18), $\widehat{S}^{(1)}(j+1)$ is the predicted value corresponding to sequence $j$, where $j=1,2, \ldots, b-1, b$.

2.1. Model Analysis. The prediction accuracy and error of equation (18) are not known for the establishment of the prediction model. This section will analyze in detail from the following aspects and study its accuracy.

2.1.1. Error Analysis. The mean and variance of the original data of tunnel deformation monitoring value $F$ are as follows:

$$
\begin{aligned}
\bar{S}^{(0)} & =\frac{1}{b} \sum_{j=1}^{b} S^{(0)}(j), \\
\beta_{S}^{2} & =\frac{1}{b} \sum_{j=1}^{b}\left(S^{(0)}(j)-\bar{S}^{(0)}\right)^{2} .
\end{aligned}
$$

In equations (19) and (20), $\bar{S}^{(0)}$ is the average value of the original monitoring data and $\beta_{S}^{2}$ is the variance of the original monitoring data.

The establishment of the gray forecasting model takes the time series as the axis, and the residual analysis needs to use the sample series.

The residual sequence $\omega^{(0)}(j)$ is as follows:

$$
\omega^{(0)}(j)=S^{(0)}(j)-\widehat{S}^{(0)}(j) .
$$

Average value of $\omega^{(0)}(j)$ is as follows:

$$
\bar{\omega}^{(0)}(j)=\frac{1}{b} \sum_{j=1}^{b} \omega^{(0)}(j),
$$

The variance value of $\omega^{(0)}(j)$ is as follows: 


$$
\begin{aligned}
\beta_{\omega^{(0)}}^{2} & =\frac{1}{b} \sum_{j=1}^{b}\left(\omega^{(0)}(j)-\bar{\omega}^{(0)}(j)\right)^{2}, \\
\nu & =\frac{\beta_{\omega^{(0)}}}{\beta_{S}} \\
P & =P\left\{\left|\omega^{(0)}(j)-\bar{\omega}^{(0)}(j)\right|<0.6745 \cdot \beta_{S}\right\} .
\end{aligned}
$$

In equations (24) and (25), $v$ is the variance ratio, $P$ is the error probability, $\beta_{S}$ is the variance value of the original data of the tunnel deformation and settlement monitoring value $S$, and $\beta_{\omega^{(0)}}$ is the mean square error of the residual sequence $\omega^{(0)}(j)$.

2.1.2. Relevance Analysis. Correlation analysis is mainly to establish the mutual influence relationship between the predicted value and the monitored value and calculate the accuracy of the model through the correlation calculation. The calculation is as follows.

From equation (18), we get

$$
\left\{\begin{array}{l}
\widehat{S}^{(0)}(j)=\left\{\widehat{S}^{(0)}(1), \widehat{S}^{(0)}(2), \ldots, \widehat{S}^{(0)}(b-1), \widehat{S}^{(0)}(b)\right\}, \\
S^{(0)}(j)=\left\{S^{(0)}(1), S^{(0)}(2), \ldots, S^{(0)}(b-1), S^{(0)}(b)\right\} .
\end{array}\right.
$$

Relevance calculation is as follows:

$$
\xi(j)=\left\{\begin{array}{l}
\frac{\min \left\{\left|S^{(0)}(j)-S^{(0)}(j)\right|\right\}+\chi \max \left\{\left|S^{(0)}(j)-S^{(0)}(j)\right|\right\}}{\left\{\left|S^{(0)}(j)-S^{(0)}(j)\right|\right\}+\chi \max \left\{\left|S^{(0)}(j)-S^{(0)}(j)\right|\right\}}, \quad j>0, \\
1, \quad j=0 .
\end{array}\right.
$$

In equation (27), $\xi(j)$ is the correlation coefficient, $\left|\widehat{S}^{(0)}(j)-S^{(0)}(j)\right|$ is the absolute error value, $\min \left\{\left|\widehat{S}^{(0)}(j)-S^{(0)}(J)\right|\right\}$ is the minimum absolute error, $\max \left\{\left|\widehat{S}^{(0)}(j)-S^{(0)}(j)\right|\right\}$ is the maximum absolute error, and $\chi$ is the error accuracy coefficient, generally 0.5 .

Solving equation (27), the correlation degree can be obtained as

$$
G=\left\{b^{-1} \sum_{j=1}^{b} \xi_{j}, j>0,1, j=0 .\right.
$$

Equation (18) is the calculation formula for the degree of relevance. Equation (28) is obtained by combining equations (26) and (27). Therefore, the $G$ value is uniquely determined, and the $R$ value represents the prediction accuracy; the larger the value, the much higher the precision.

\section{Typical Case Analysis and Support Design}

3.1. Analysis of Typical Cases. This paper relies on the Duimenzhai Tunnel on the left line, the ground elevation of the project is $1310 \mathrm{~m} \sim 1390 \mathrm{~m}$, the relative elevation difference is $80 \mathrm{~m}$, and the mileage is ZK190+780 ZK191 + 275 . The geological structure is complex, with well-developed rock folds, joints, and cracks, active faults fractures are developed, and the rock mass is relatively broken. The surrounding rock is prone to instability and failure. And the deformation of the tunnel increases with time. The geological longitudinal section is shown in Figure 1, and the layout of monitoring and measuring points is shown in Figure 2. The gray model is used to predict the tunnel deformation, and the results are shown in Table 1.

In order to more intuitively study the relationship between the tunnel deformation monitoring value and the predicted value, programming drawing software is used to draw the predicted values of $S_{1}$ (left), $S_{1}$ (right), $S_{2}$ (left), $S_{2}$ (right), and the vault, respectively. The monitoring value trend chart is shown in Figure 3.

3.1.1. Forecast Duration Analysis. The data in Figure 3 show that, at $S_{1}$ (left), the inflection point occurs on the 7 th day $(8 \mathrm{~d})$, the error probabilities $P_{H 1}=0.42$ and $P_{H 2}=0.43$, and the correlation coefficients $R_{H 1}=0.68$ and $R_{H 2}=0.67$; at $S_{1}$ (right), the inflection point occurs on the $7^{\text {th }}$ day, the error probability $P_{F}=0.41$, and the correlation coefficient $R_{F}=0.69$; at $S_{2}$ (left), the inflection point occurs on the $6 \mathrm{~d}$, the error probability $P_{E}=0.42$, and the correlation coefficient $R_{E}=0.72$; at $S_{2}$ (right), the inflection point occurs on the 6th day, the error probability $P_{J}=0.38$, and the correlation coefficient $R_{J}=0.71$; and at the vault, the inflection point occurs on the 6th day, the error probability $P_{A}=0.41$, and the correlation coefficient $R_{A}=0.67$.

At $S_{1}$ (left) and $S_{1}$ (right), the error inflection points occurred on the $7^{\text {th }}$ day of prediction, and the prediction error inflection points at $S_{2}$ (left), $S_{2}$ (right), and the tunnel vault all occurred on the 6th day of prediction; at $S_{1}$ (left), $S_{1}$ (right), $S_{2}$ (left), $S_{2}$ (right), and the vault, $P$ and $R$ are closer; comprehensive analysis and gray prediction belongs to a short-term prediction model; the prediction time is about 6 days; beyond this range, the prediction error and correlation coefficient are all great changes that have occurred, so it is recommended that if the gray model is used to predict tunnel deformation, the prediction duration should be controlled.

3.1.2. Error Analysis. Figure 3 shows that the predicted value is close to the monitored value, and the maximum error is only $2.99 \%$. If the forecast time becomes longer, the error reaches $5.67 \%$ on the $9^{\text {th }}$ day. Although the error is within the allowable range, the error increases with time.

3.1.3. Correlation Analysis. The data in Figure 3 show that, at $S_{1}$ (left), there is an associated area from $7 \mathrm{~d}$ to $8 \mathrm{~d}$. In this area, $P$ and $R$ are close, $P_{H 1}=0.42, P_{H 2}=0.43, R_{H 1}=0.68$, and $R_{H 2}=0.67$; at $S_{1}$ (right), there is an associated area from $3 \mathrm{~d}$ to $4 \mathrm{~d}, P_{G 1}=0.41, P_{G 2}=0.40, R_{G 1}=0.65$, and $R_{G 2}=0.67$; at $S_{2}$ (left), there is an associated area from $2 \mathrm{~d}$ to $3 \mathrm{~d}$, $P_{M 1}=0.38, P_{G 2}=0.37, R_{M 1}=0.71$, and $R_{M 2}=0.70 ;$ at $S_{2}$ (right), there is an associated area from $3 \mathrm{~d}$ to $4 \mathrm{~d}, P_{K 1}=0.39$, 


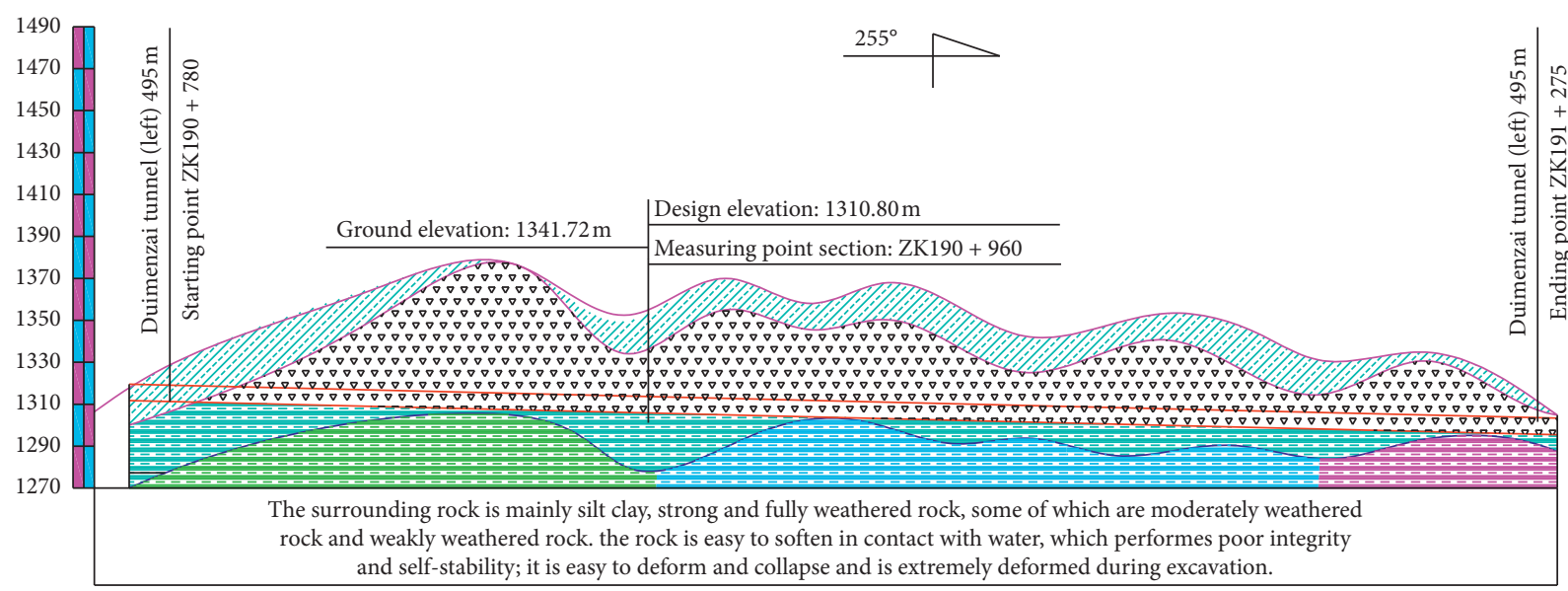

\begin{tabular}{|c|c|c|c|}
\hline =ニニ目 & Strongly differentiated mudstone & =-二目 & Fully differentiated mudstone \\
\hline 牙目 & Moderately differentiated mudstone & & Powder clay \\
\hline =--目 & Moderately differentiated mudstone & 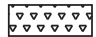 & Sand rock \\
\hline
\end{tabular}

FIgURE 1: Schematic map of geological profile design (unit: m).

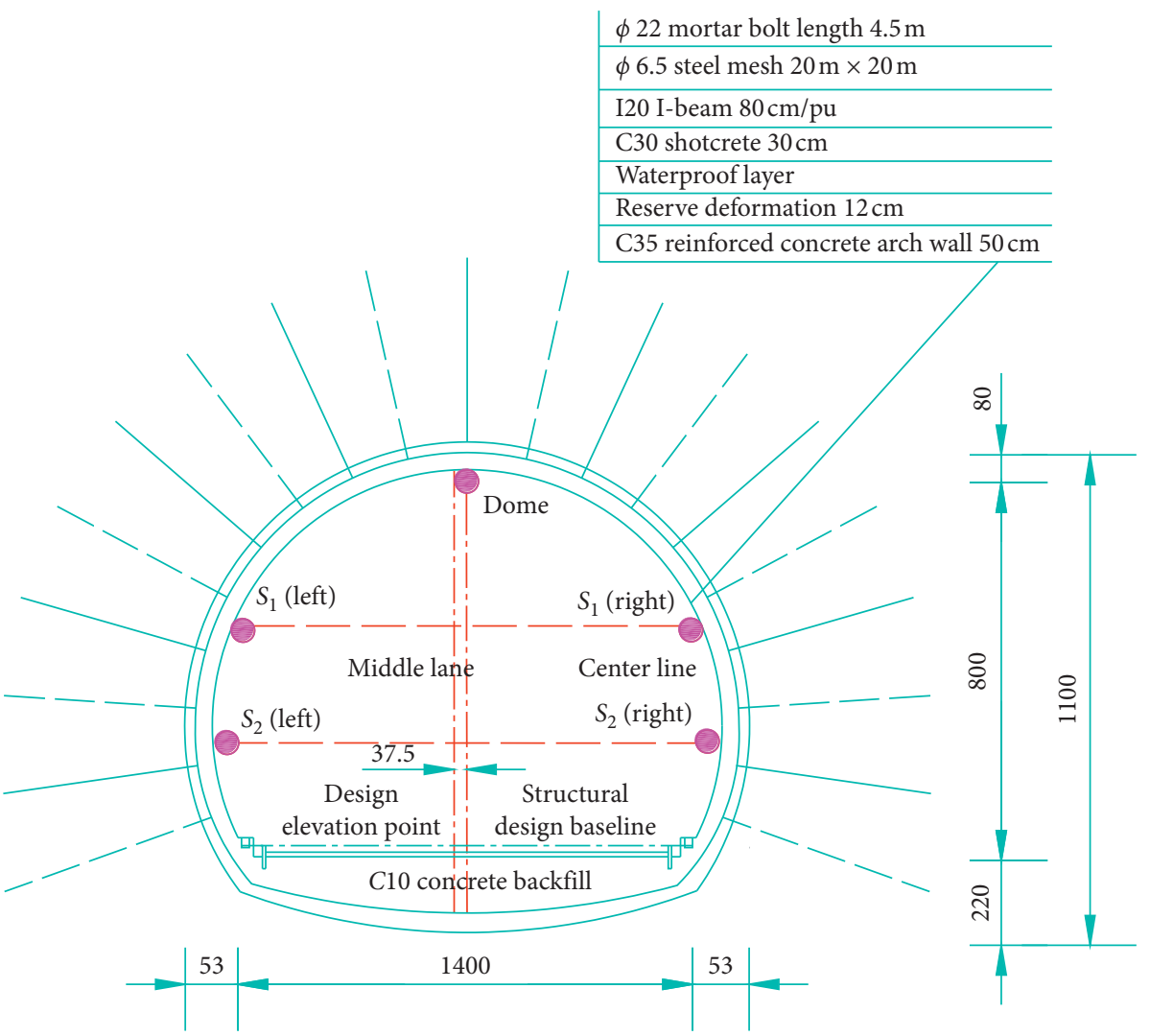

FIgURE 2: Schematic diagram of measuring point layout (unit: $\mathrm{cm}$ ).

$P_{K 2}=0.40, R_{K 1}=0.69$, and $R_{K 2}=0.70$; and there is no associated area at the vault.

Associated areas appear at $S_{1}$ (left), $S_{1}$ (right), $S_{2}$ (left), and $S_{2}$ (right), indicating that the tunnel deformation in this area is in a gentle state, and the deformation hardly increases with time. It is relatively safe to carry out tunnel construction at this moment; Figure 3(e) shows that the deformation of the vault increases with time, and after the $6^{\text {th }}$ day, its deformation is relatively slower; comprehensive analysis shows that the design of the support at the maximum deformation 
TABLE 1: Tunnel deformation monitoring data.

\begin{tabular}{|c|c|c|c|c|c|c|c|c|c|c|}
\hline \multirow{2}{*}{$\begin{array}{l}\text { Time } \\
\text { (d) }\end{array}$} & \multicolumn{2}{|c|}{$S_{1}$ (left) } & \multicolumn{2}{|c|}{$S_{1}$ (right) } & \multicolumn{2}{|c|}{$S_{2}$ (left) } & \multicolumn{2}{|c|}{$S_{2}$ (right) } & \multicolumn{2}{|c|}{ Dome } \\
\hline & $\begin{array}{l}\text { Monitoring } \\
\text { value }(\mathrm{m})\end{array}$ & $\begin{array}{l}\text { Predictive } \\
\text { value }(\mathrm{m})\end{array}$ & $\begin{array}{l}\text { Monitoring } \\
\text { value }(\mathrm{m})\end{array}$ & $\begin{array}{l}\text { Predictive } \\
\text { value }(\mathrm{m})\end{array}$ & $\begin{array}{l}\text { Monitoring } \\
\text { value }(\mathrm{m})\end{array}$ & $\begin{array}{l}\text { Predictive } \\
\text { value }(\mathrm{m})\end{array}$ & $\begin{array}{l}\text { Monitoring } \\
\text { value }(\mathrm{m})\end{array}$ & $\begin{array}{l}\text { Predictive } \\
\text { value }(\mathrm{m})\end{array}$ & $\begin{array}{l}\text { Monitoring } \\
\text { value }(\mathrm{m})\end{array}$ & $\begin{array}{l}\text { Predictive } \\
\text { value }(\mathrm{m})\end{array}$ \\
\hline 1 & 50 & 50.03 & 45 & 45.06 & 121 & 121.34 & 95 & 95.39 & 44 & 44.05 \\
\hline 2 & 60 & 62.25 & 65 & 60.30 & 188 & 190.36 & 123 & 125.46 & 55 & 55.08 \\
\hline 3 & 99 & 110.38 & 95 & 99.02 & 189 & 193.56 & 151 & 153.47 & 79 & 81.00 \\
\hline 4 & 150 & 153.42 & 101 & 103.40 & 236 & 240.63 & 153 & 154.65 & 111 & 113.02 \\
\hline 5 & 197 & 200.96 & 127 & 129.36 & 251 & 256.37 & 161 & 163.45 & 131 & 134.05 \\
\hline 6 & 240 & 243.50 & 146 & 147.56 & 256 & 259.78 & 167 & 168.94 & 145 & 149.69 \\
\hline 7 & 279 & 283.00 & 160 & 164.30 & 258 & 265.96 & 168 & 172.99 & 150 & 154.87 \\
\hline 8 & 281 & 285.30 & 184 & 190.36 & 259 & 266.97 & 178 & 184.74 & 153 & 156.40 \\
\hline 9 & 307 & 312.50 & 185 & 195.39 & 262 & 269.35 & 179 & 189.92 & 155 & 159.90 \\
\hline
\end{tabular}

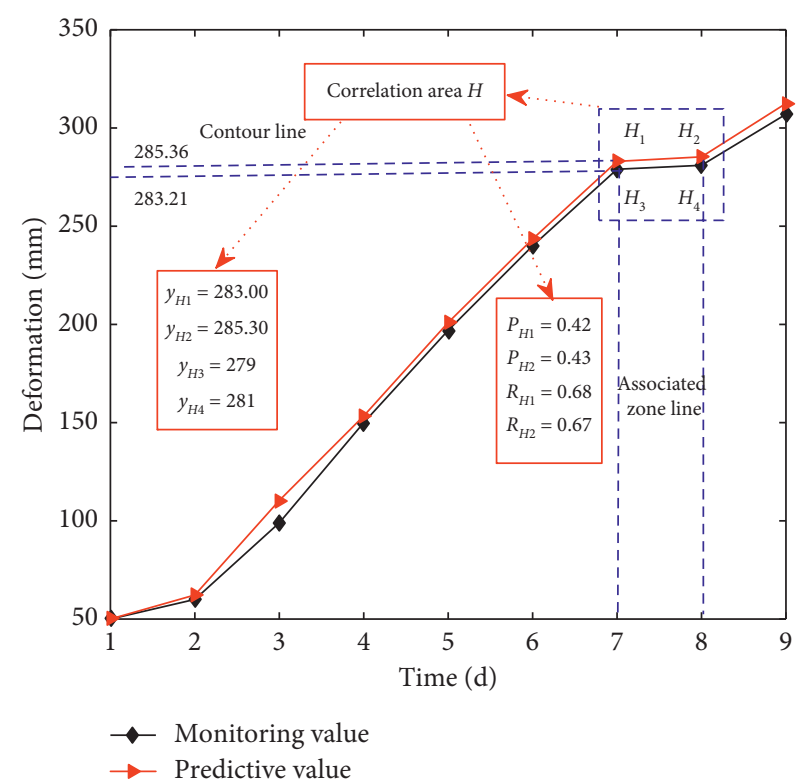

(a)

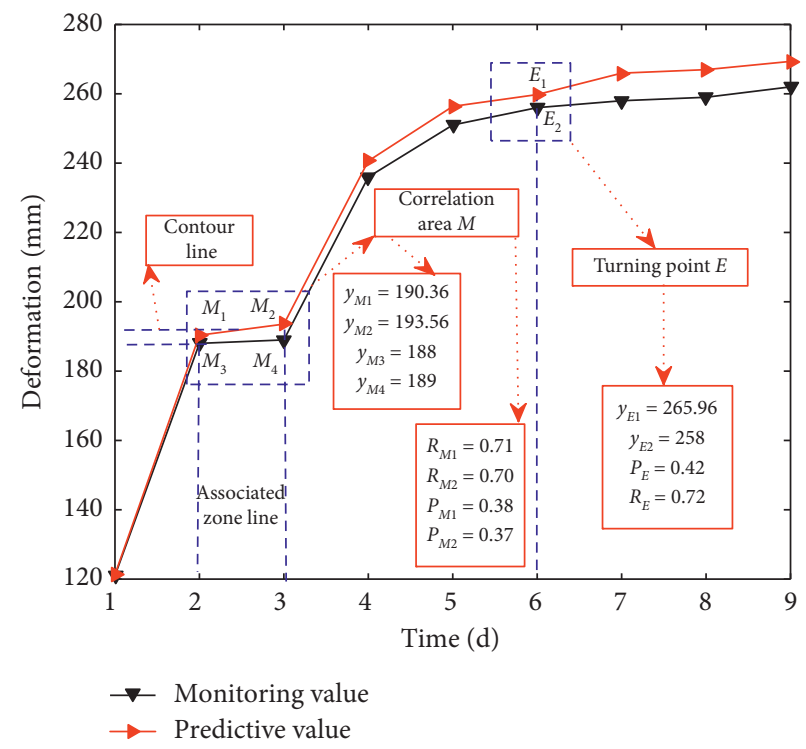

(c)

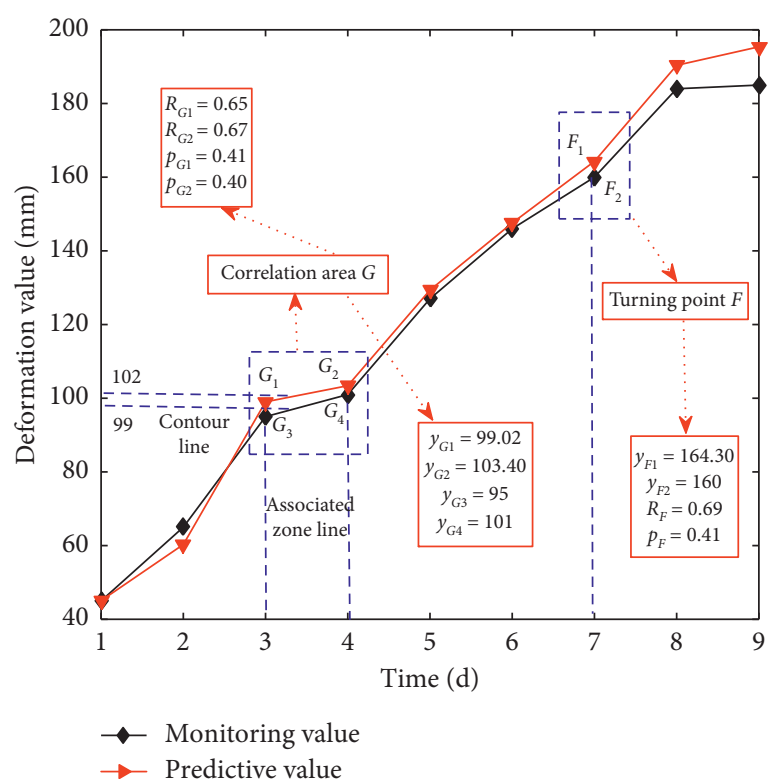

(b)

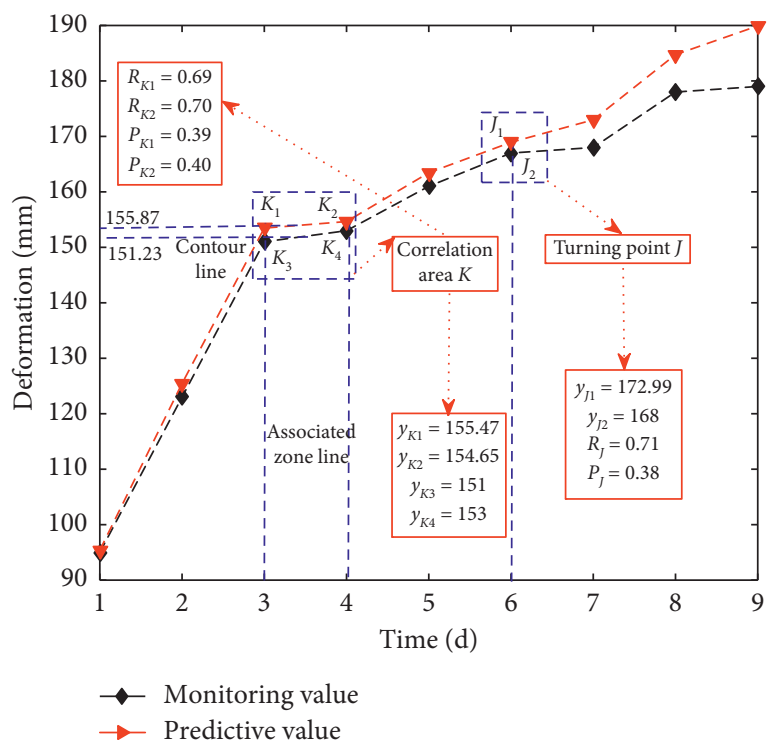

(d)

Figure 3: Continued. 


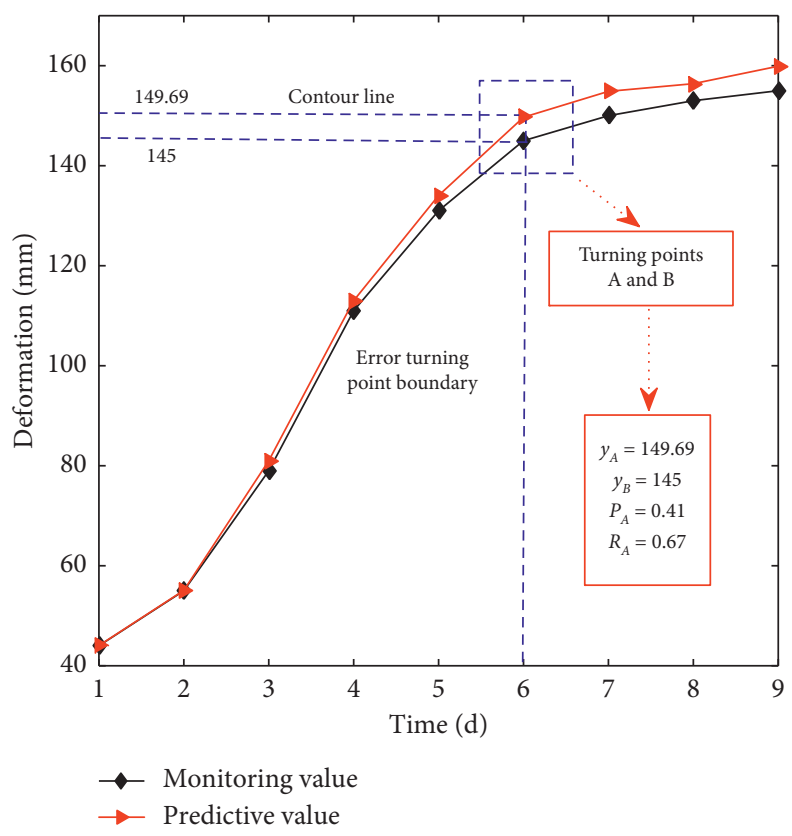

(e)

Figure 3: Schematic diagram of comparative analysis of tunnel deformation prediction value and monitoring value: (a) $S_{1}$ (left); (b) $S_{1}$ (right); (c) $S_{2}$ (left); (d) $S_{2}$ (right); (e) dome.

in the associated area is very important for the safe construction of the tunnel, and it can prevent large settlement of the vault.

The proposed tunnel is located in a soft rock area, and the surrounding rock grade is Grade V. Figure 3 shows that the deformation of the tunnel increases with time, and the maximum predicted value reaches $S_{\max \cdot R}=312.50 \mathrm{~mm}$. If effective treatment measures are not taken, the safety of tunnel construction will be endangered. In the following part, the author will design the support measures at $S_{\max \cdot R}$ using numerical simulation to compare and analyze $S_{\max \cdot M}$ and $\sigma_{\text {max }} M$ generated by the surrounding rock under different support conditions and giving optimal support recommendations.

\subsection{Design of Support Measures at $S_{\max \cdot R}$}

3.2.1. Selection of Support Methods. The mechanical mechanism of the conventional mortar bolt and the resin bolt support is the same [33], but the force transmission effect of the resin bolt is slightly weaker than that of the mortar bolt, and the pulling force is smaller, as shown in Figure 4. However, resin bolts also have some advantages as a means of tunnel support:

(1) In terms of anchoring force, the anchoring force of resin anchors is equivalent to that of mortar anchors of the same specification. For example, the anchoring force of $\varphi 15 \mathrm{~mm}$ resin anchors can reach $50 \mathrm{kN} \sim 75 \mathrm{kN}$, which can provide sufficient anchoring force to effectively control the surrounding rock deformation.

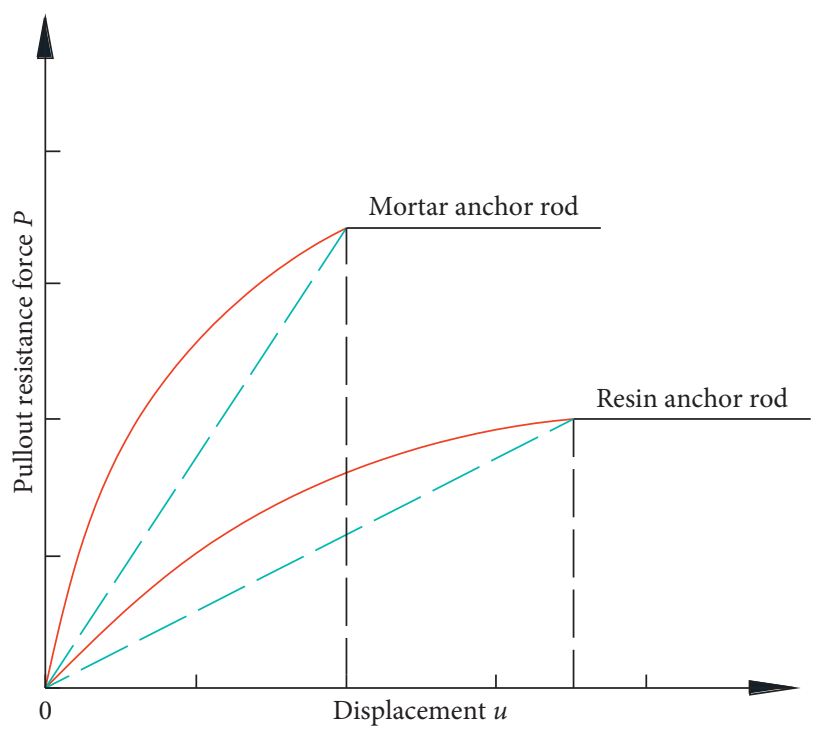

FIGURE 4: Displacement curves of resin anchor and mortar anchor.

(2) In terms of processability, the resin anchor rod is a composite material composed of unsaturated polyester resin as the matrix material and glass fiber as the reinforcing material; it has high tensile strength, but low shear resistance and good cutting performance, and no spark. Ordinary mortar anchor rods are prone to damage the processing machinery (such as being involved in the drum to damage the pick) during the cutting and processing of the support site, and sparks are prone to occur during the cutting and processing of the construction site, which poses 
TABle 2: Physical and mechanical parameters of rock mass.

\begin{tabular}{lcccccc}
\hline $\begin{array}{l}\text { Surrounding rock } \\
\text { category }\end{array}$ & $\begin{array}{c}\text { Layer thickness } \\
(\mathrm{m})\end{array}$ & $\begin{array}{c}\text { Weight } \\
\left(\mathrm{kN} \mathrm{m}^{-3}\right)\end{array}$ & $\begin{array}{c}\text { Elastic modulus } \\
(\mathrm{GPa})\end{array}$ & $\begin{array}{c}\text { Poisson's } \\
\text { ratio }\end{array}$ & $\begin{array}{c}\text { Cohesion } \\
(\mathrm{MPa})\end{array}$ & $\begin{array}{c}\text { Internal friction angle } \\
\left({ }^{\circ}\right)\end{array}$ \\
\hline Powder clay & 14 & 20.4 & 0.042 & 0.25 & 1.46 & 46 \\
Sand stone & 27 & 17.3 & 0.014 & 0.32 & 0.026 & 30 \\
Argillaceous rock & 19 & 16.5 & 0.006 & 0.35 & 0.043 & 37 \\
Ordinary mortar bolt & - & 81.3 & 200 & 0.30 & - & - \\
Resin anchor & - & 76.6 & 280 & 0.28 & - & - \\
\hline
\end{tabular}

TABLE 3: Bolt support parameters.

\begin{tabular}{lcccc}
\hline Anchor types & Length $(\mathrm{m})$ & Ring distance $(\mathrm{m})$ & Longitudinal distance $(\mathrm{m})$ & Diameter $(\mathrm{mm})$ \\
\hline Mortar bolt & 4.5 & 1.0 & 1.0 & $\varphi 22$ \\
Resin anchor & 4.5 & 1.0 & 1.0 & $\varphi 22$ \\
\hline
\end{tabular}

TABLE 4: Encrypted bolt support parameters.

\begin{tabular}{lcccc}
\hline Anchor types & Length $(\mathrm{m})$ & Ring distance $(\mathrm{m})$ & Longitudinal distance $(\mathrm{m})$ & Diameter $(\mathrm{mm})$ \\
\hline Mortar bolt & 4.5 & 0.7 & 0.7 & $\varphi .7$ \\
Resin anchor & 4.5 & 0.7 & 0.4 & $\varphi 22$ \\
Mortar bolt & 4.5 & 0.4 & 0.4 & $\varphi 22$ \\
Resin anchor & 4.5 & 0.4 & & $\varphi 22$ \\
\hline
\end{tabular}

TABLE 5: Parameters of lengthened bolt support.

\begin{tabular}{lcccc}
\hline Anchor types & Length $(\mathrm{m})$ & Ring distance $(\mathrm{m})$ & Longitudinal distance $(\mathrm{m})$ & Diameter $(\mathrm{mm})$ \\
\hline Mortar bolt & 7.5 & 1.0 & 1.0 & $\varphi 22$ \\
Resin anchor & 7.5 & 1.0 & 1.0 & $\varphi 22$ \\
Mortar bolt & 6.0 & 1.0 & 1.0 & $\varphi 22$ \\
Resin anchor & 6.0 & 1.0 & 1.0 & $\varphi 22$ \\
\hline
\end{tabular}

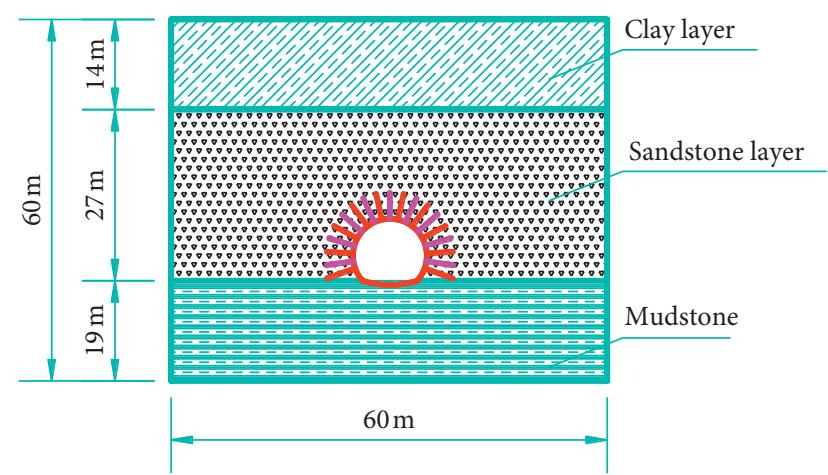

FIgURE 5: Model size diagram.

safety hazards such as fire and explosion in special geological sections.

(3) In terms of dead weight, the density of resin anchor rods is generally about $2.0 \mathrm{~g} / \mathrm{cm}^{3}$, which is equivalent to $1 / 4$ of conventional metal anchor rods. Therefore, resin anchor rods are lighter in handling, less difficult to transport, and faster, achieving the purpose of timely construction, improving construction efficiency and construction schedule.

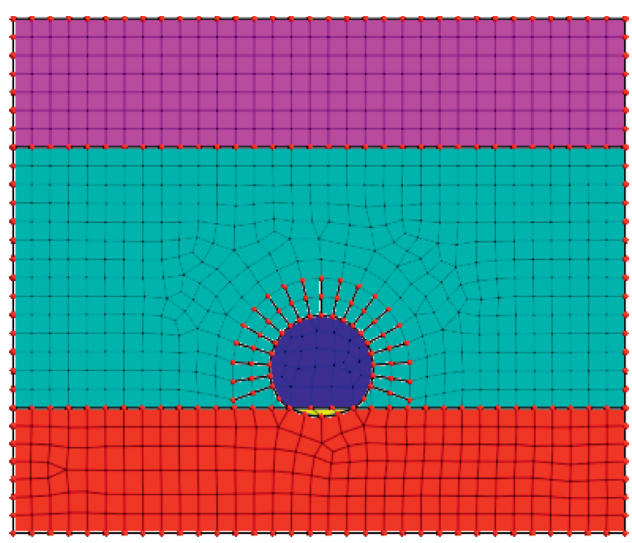

Figure 6: Mesh division.

For these reasons, in the design of supporting measures below, we plan to compare the control effects of resin bolts and mortar bolts on surrounding rock deformation to determine whether resin bolts can be used as one of the options for controlling large deformation of soft rock tunnels, so as to give reasonable support recommendations. 


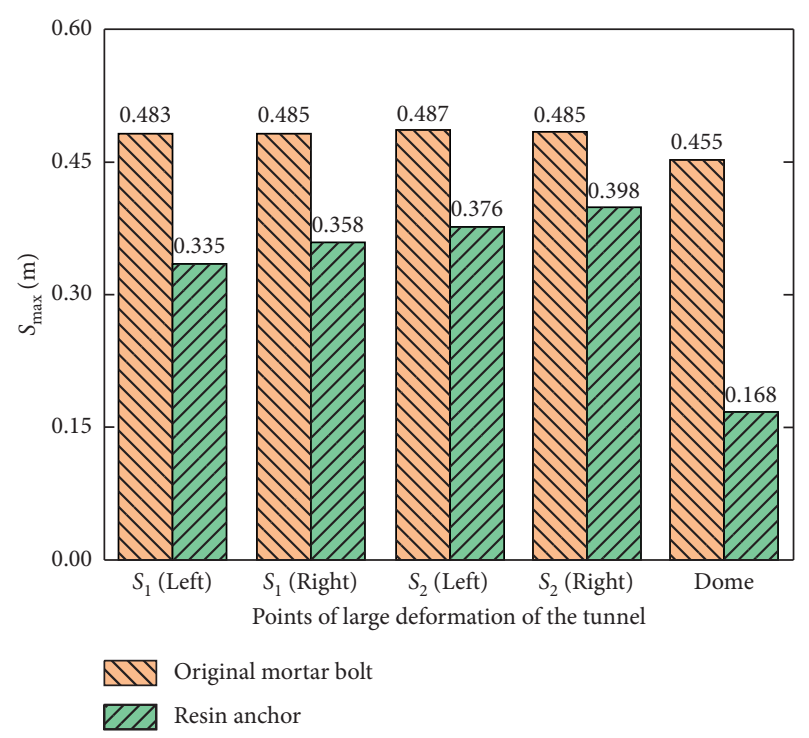

(a)

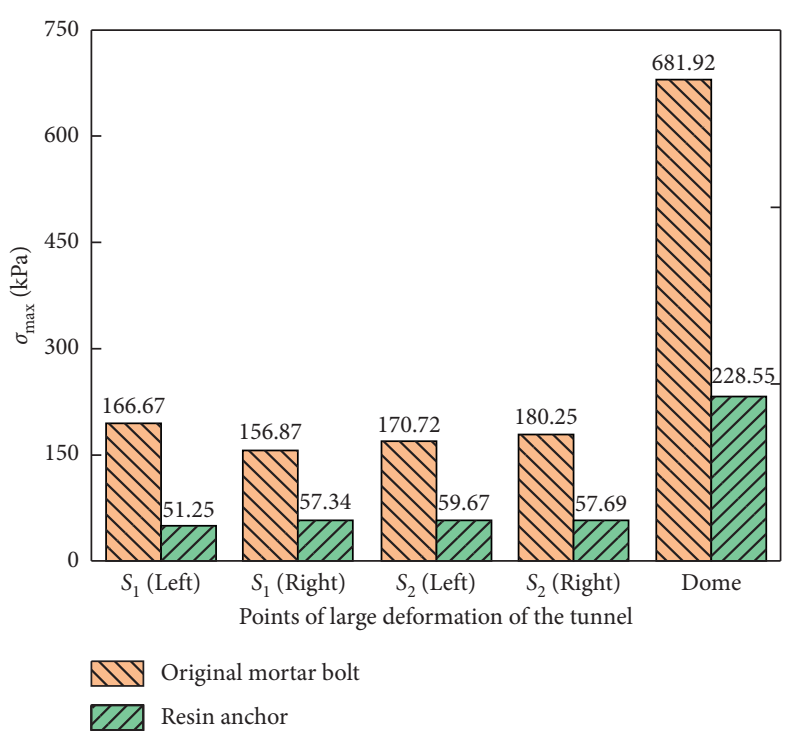

(b)

FIGURE 7: Original parameter mortar bolt and resin bolt support: (a) $S_{\max }$ of dangerous point; (b) $\sigma_{\max }$ of dangerous point.

3.2.2. Supporting Parameters. The supporting project was originally designed for spray-anchor support; the circumferential arrangement of anchor rods is $1.0 \mathrm{~m}$ apart, after the small pipes are grouted and consolidated; the upper, middle, and lower step method is used for weak blasting excavation or mechanical excavation. Physical and mechanical parameters of related materials are shown in Table 2. As shown in Figure 3(a), when the original design support is adopted, the tunnel deformation is large, according to the gray model prediction, and the maximum predicted value $S_{\max \cdot R}=312.50 \mathrm{~mm}$. For $S_{\max \cdot \mathrm{R}}$, the following bolt supports are designed:

(1) Design resin bolts with the same parameters as the original mortar bolts and analyze the effect of the resin bolts and mortar bolts on controlling surrounding rock deformation through numerical simulation. The supporting parameters are shown in Table 3.

(2) Change the $L$ and $d$ of the mortar bolt and the resin bolt, study the $S_{\max \cdot M}$ and $S_{\max \cdot M}$ produced by the surrounding rock based on the numerical method, and give the optimal support recommendations. The support parameters can be seen in Tables 4 and 5 .

3.2.3. Model Establishment. Using FLAC3D finite element software, a two-dimensional numerical model of the Duimenzhai Tunnel is established. After considering the excavation of an underground tunnel, only the rock mass within the excavation range of 5 times the size of the tunnel has a disturbing effect, and the tunnel height of this project is $11.58 \mathrm{~m}$, and the width is $10.60 \mathrm{~m}$. Therefore, the height $\times$ width of the proposed model is $60 \mathrm{~m} \times 60 \mathrm{~m}$, and the model size and grid division are shown in Figures 5 and 6 .
3.2.4. Analysis of Surrounding Rock Stress and Displacement. Figure 7 shows that when the mortar bolt is used to support the tunnel, $S_{\max \cdot M}=0.487 \mathrm{~cm}$ and $\sigma_{\max \cdot M}=681.92 \mathrm{kN} / \mathrm{m}^{2}$; when the resin bolt is used to support the tunnel, $S_{\max \cdot M}=0.398 \mathrm{~cm}$ and $\sigma_{\max \cdot M}=228.55 \mathrm{kN} / \mathrm{m}^{2}$.

The results show that compared with the tunnel supported by mortar bolts, $S_{\max \cdot M}$ is reduced by $22.36 \%$ and $\sigma_{\max \cdot M}$ is reduced by $66.48 \%$ for resin bolts. The supporting effect of resin bolts is significant.

Figure 8 shows that when the mortar bolts are used to support the tunnel, $S_{\max \cdot M}=0.320 \mathrm{~m}$ and $\sigma_{\max \cdot M}=220.55 \mathrm{kN} / \mathrm{m}^{2}$; when the resin bolts are used to support the tunnel, $S_{\max \cdot M}=0.177 \mathrm{~m}$ and $\sigma_{\max \cdot M}=183.65 \mathrm{kN} / \mathrm{m}^{2}$.

The results show that compared with mortar bolts support, $S_{\max \cdot M}$ is reduced by $32.46 \%$ and $\sigma_{\max \cdot M}$ is reduced by $47.08 \%$, and its supporting effect is significant.

Figure 9 shows that when the mortar bolts are used to support the tunnel, $S_{\max \cdot M \cdot}=0.114 \mathrm{~m}$ and $\sigma_{\text {max } \cdot M}=243.38 \mathrm{kN} / \mathrm{m}^{2}$; when the resin bolts are used to support the tunnel, $S_{\max \cdot M}=0.077 \mathrm{~m}$ and $\sigma_{\max } \cdot M=128.80 \mathrm{kN} / \mathrm{m}^{2}$.

The results show that compared with mortar bolt support, resin bolts have a reduction of $S_{\max \cdot M}$ by $44.68 \%$ and a reduction of $\sigma_{\max M}$ by $16.73 \%$. The supporting effect is significant.

Figure 10 shows that when the mortar bolts are used to support the tunnel, $S_{\max \cdot M}=0.078 \mathrm{~m}$ and $\sigma_{\text {max }} M=165.38 \mathrm{kN} / \mathrm{m}^{2}$; when the resin bolt is used to support the tunnel, $S_{\max \cdot M}=0.036 \mathrm{~m}$ and $\sigma_{\max \cdot M}=87.99 \mathrm{kN} /$ $\mathrm{m}^{2}$.The results show that compared with mortar bolts support, $S_{\max \cdot M}$ is reduced by $53.85 \%$ and $\sigma_{\max \cdot M}$ is reduced by $46.80 \%$, and its supporting effect is significant.

Figure 11 shows that when the mortar bolts are used to support the tunnel, $S_{\max \cdot M}=0.056 \mathrm{~m}$ and $\sigma_{\max \cdot M}=148.55 \mathrm{kN} /$ 


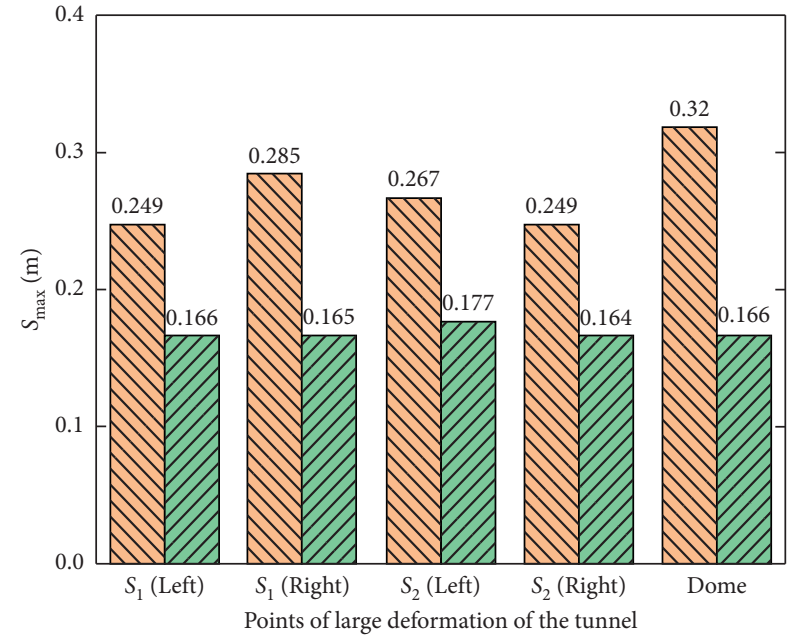

DV Mortar bolt DD Resin anchor

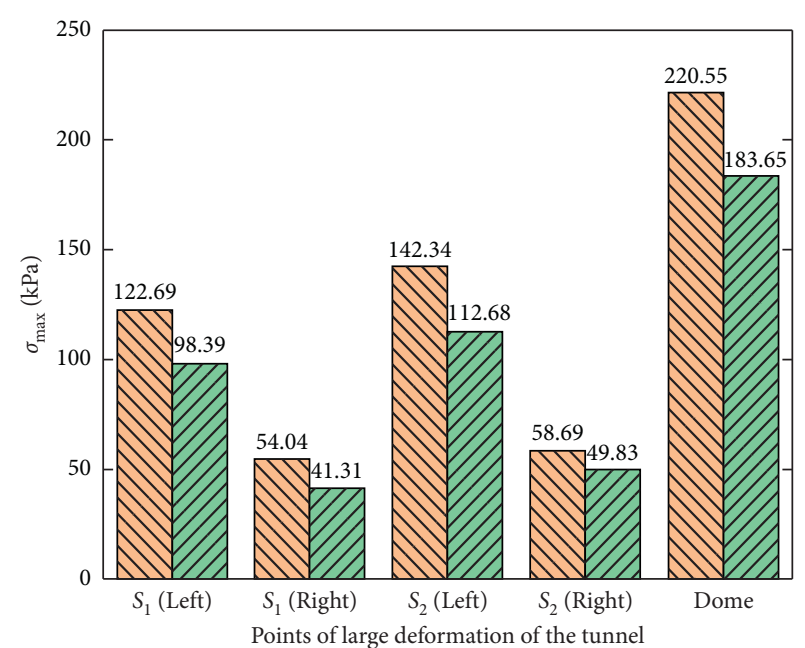

DV Mortar bolt

VIA Resin anchor

(a)

(b)

FIgURE 8: The distance between mortar bolt and resin bolt support is reduced to $0.7 \mathrm{~m}$ : (a) $S_{\max }$ of dangerous point; (b) $\sigma_{\max }$ of dangerous point.

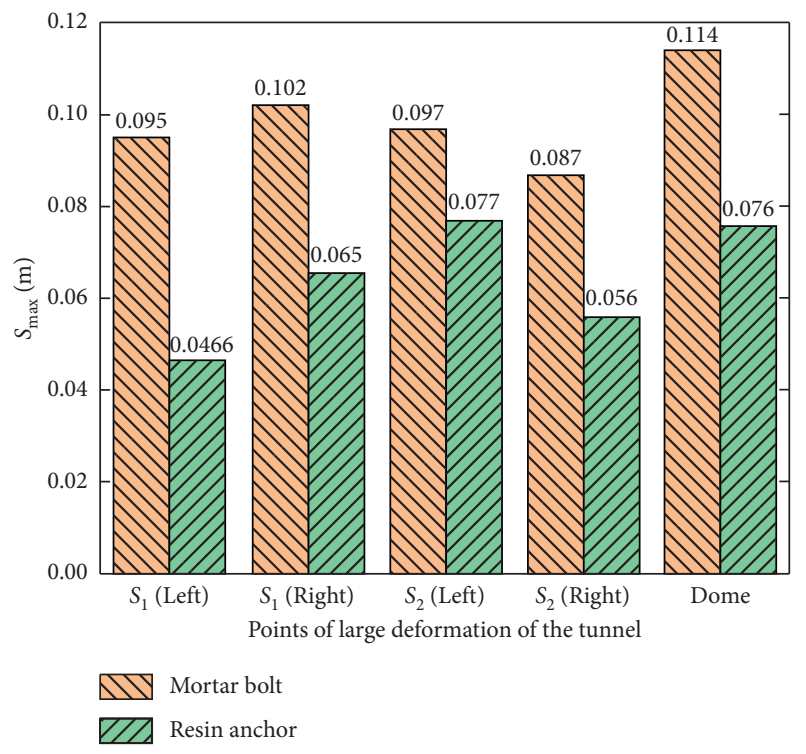

(a)

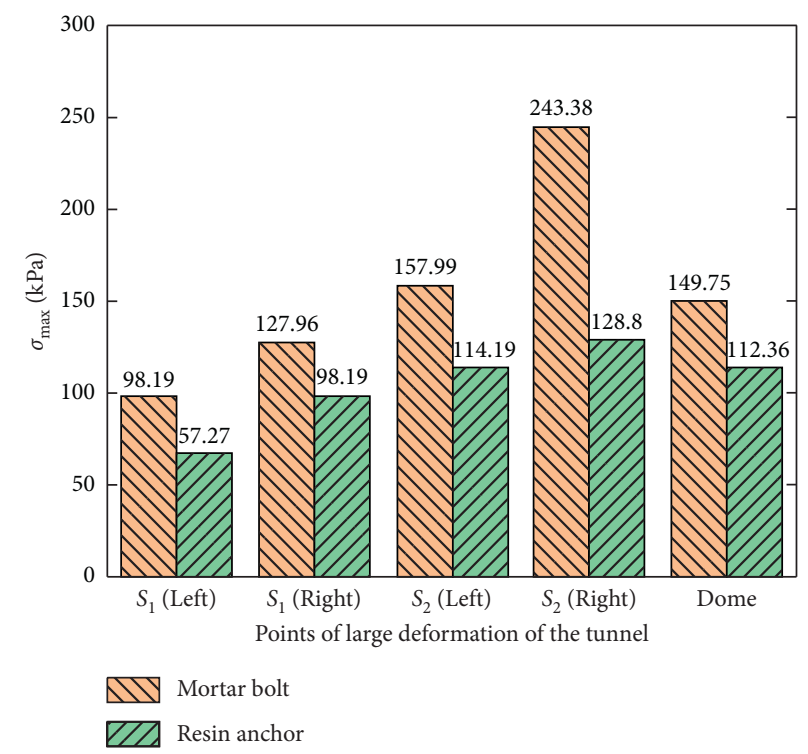

(b)

FIgURE 9: The distance between mortar bolt and resin bolt support is reduced to $0.4 \mathrm{~m}$ : (a) $S_{\max }$ of dangerous point; (b) $\sigma_{\max }$ of dangerous point.

$\mathrm{m}^{2}$; when the resin bolts are used to support the tunnel, $S_{\text {max } M}=0.032 \mathrm{~m}$ and $\sigma_{\max \cdot M}=95.65 \mathrm{kN} / \mathrm{m}^{2}$.

The results show that compared with the tunnel supported by mortar bolts, the $S_{\max \cdot M}$ is reduced by $42.85 \%$ and the $\sigma_{\max \cdot M}$ is reduced by $35.61 \%$, and the supporting effect is significantly improved.

From the comparative analysis of Figures 5-9, when mortar bolts are used for support, $S_{\max \cdot M}$ and $\sigma_{\max \cdot M}$ are approximately 1.6 times and 3 times than that of resin bolts support; Figures 6 and 7 are compared with Figure 5, the surrounding rock deformation decreases with the reduction of the bolt spacing, and when it is reduced to $0.4 \mathrm{~m} \sim 0.7 \mathrm{~m}$, the resin bolt support has a significant effect on controlling the surrounding rock deformation; Figures 8 and 9 are compared with Figure 5; when the length of the bolt is $4.5 \mathrm{~m}$ $\sim 6 \mathrm{~m}$, the effect of using resin bolt support to control surrounding rock deformation is significant, but with the increase in the length of the bolt, the mortar bolts or the resin anchor effect of rod support in controlling the deformation of surrounding rock is small. 


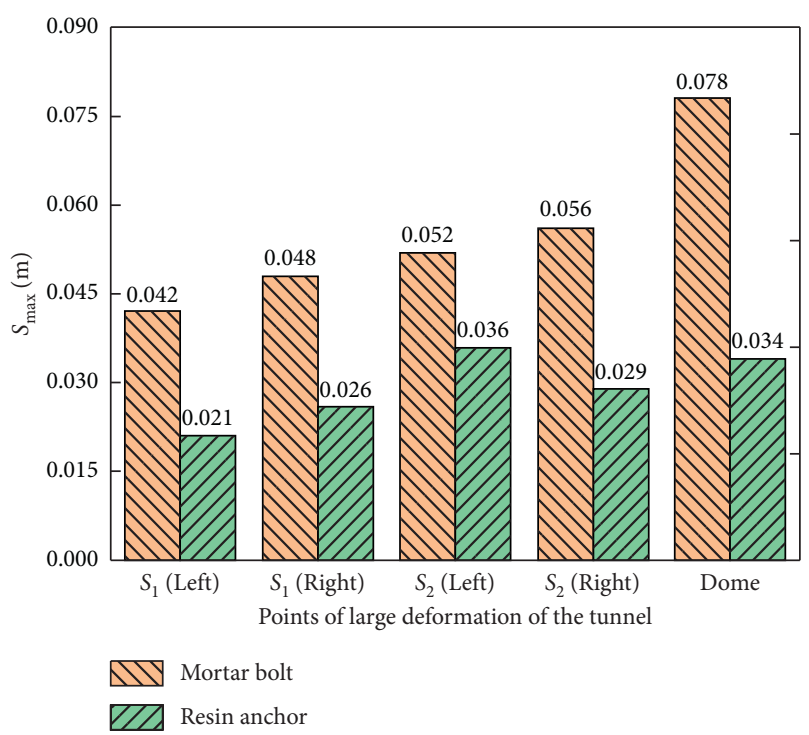

(a)

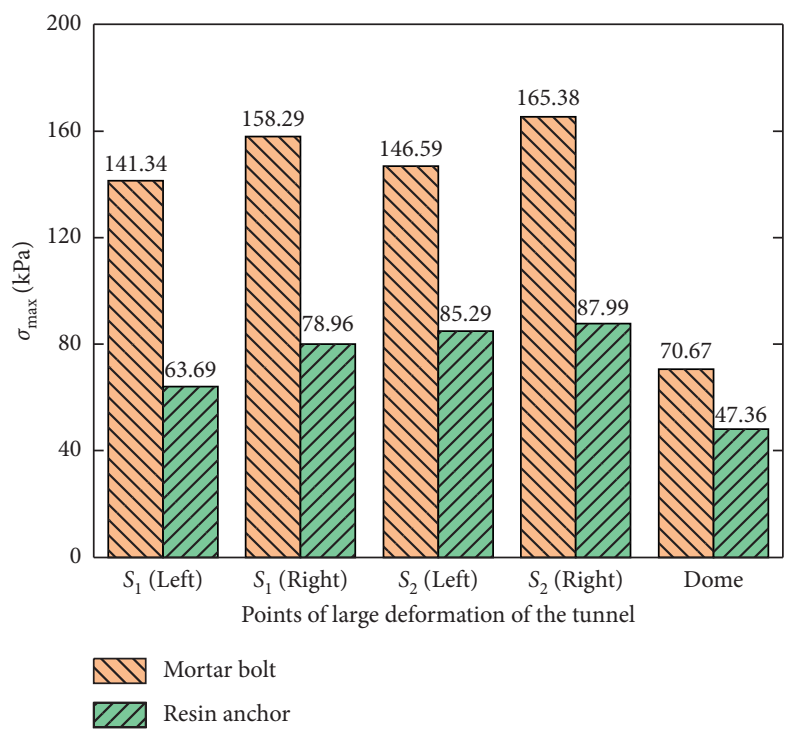

(b)

FIGURE 10: The length of mortar bolt and resin bolt support is $6.0 \mathrm{~m}$ : (a) $S_{\max }$ of dangerous point; (b) $\sigma_{\max }$ of dangerous point.

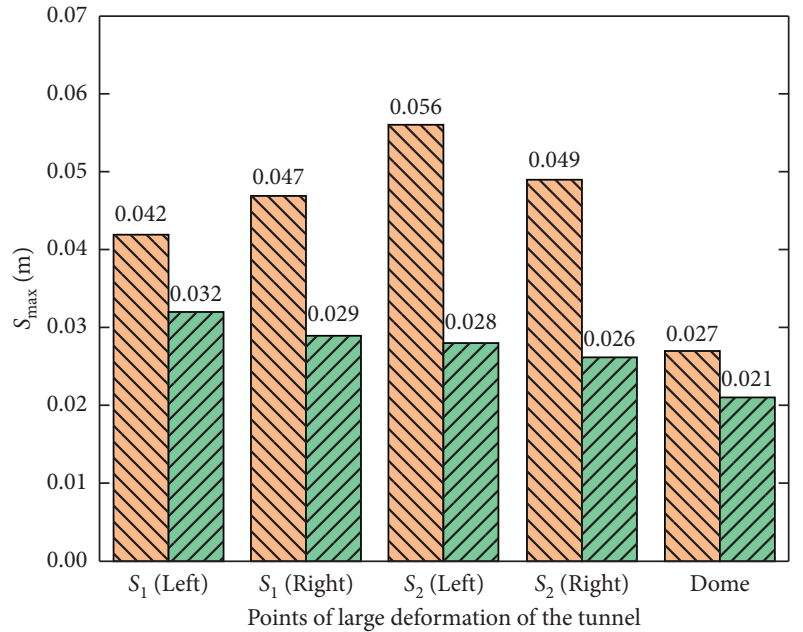

DV Mortar bolt

VID Resin anchor

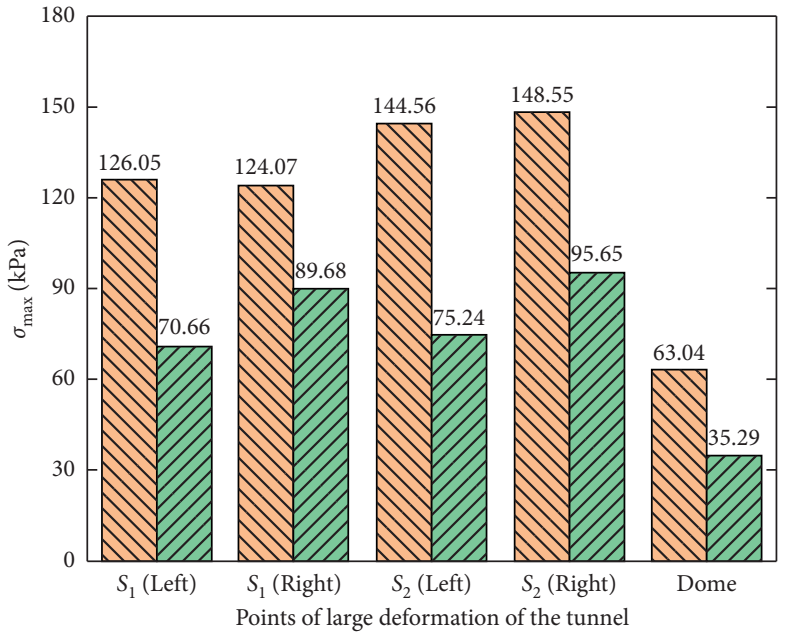

N1V Mortar bolt

DID Resin anchor

(a)

(b)

FIGURE 11: The length of mortar bolt support and bolt support is $7.5 \mathrm{~m}$ : (a) $S_{\max }$ of dangerous point; (b) $\sigma_{\max }$ of dangerous point.

\section{Conclusion}

The gray theory is used to derive new tunnel deformation and monitoring time series, combined with the differential method, matrix transformation method, least square method, and other methods, to summarize the large deformation prediction model of the soft rock tunnel and finally support design in $S_{\max \cdot R}$, numerical analysis of its supporting effect is carried out, and the relevant conclusions are as follows:

(1) After predicting the large deformation of the supporting project, it is found that the gray theory prediction model is more accurate, the best prediction time is one week, and the maximum error is not more than $3 \%$.

(2) According to $S_{\max \cdot R}$, the mortar bolts and resin bolts support are designed, and the $S_{\max \cdot M}$ and $\sigma_{\max \cdot M}$ generated by the surrounding rock under different parameters of the bolts support are analyzed by numerical software. Compared with mortar bolts, resin bolts have a more significant effect on controlling surrounding rock deformation, and $S_{\max \cdot M}$ and $\sigma_{\max \cdot M}$ can be reduced by about $50 \%$. 
(3) The study finds that when the length of the bolts is $4.5 \mathrm{~m} \sim 6 \mathrm{~m}$ and the local density range is $0.4 \mathrm{~m} \sim$ $0.7 \mathrm{~m}$, resin bolts support should be selected; for the rest, the effect of mortar bolts support and resin bolts support of difference is smaller.

(4) The shortcoming of the gray model is that it can only make short-term forecasts. If the forecasting time increases, the error will be within the allowable range of the project, but it will increase over time.

\section{Data Availability}

Data supporting the results of this study can be obtained from the corresponding author.

\section{Conflicts of Interest}

The authors declare that they have no conflicts of interest.

\section{Acknowledgments}

This paper was sponsored by the National Science Foundation of China (Grant nos. 51968010 and 51608141) and the Science and Technology Planning Project of Guizhou Province (Grant nos. [2012]63 and [2017]5788).

\section{References}

[1] T. Zhang, Research and Engineering Application of Deformation Prediction Model of Deep Foundation Pit, Changsha: Central South University, Changsha, China, 2009.

[2] M. Lei, D. Lin, Q. Huang, C. Shi, and L. Huang, "Research on the construction risk control technology of shield tunnel underneath an operational railway in sand pebble formation: a case study," European Journal of Environmental and Civil Engineering, vol. 24, no. 10, pp. 1558-1572, 2020.

[3] S. Song, Research on the Method of Bolt Ultimate Bearing Capacity Based on Improved Grey Neural Network Model, Shijiazhuang: Shijiazhuang Railway University, Shijiazhuang, China, 2018.

[4] Y. Tan, Study on the Determination of the Loose Zone of the Mining Roadway in the Complex Structural Zone and the Support Strategy, Anhui University of Science and Technology, Huainan, China, 2009.

[5] M. Lei, J. Liu, Y. Lin, C. Shi, and C. Liu, "Deformation characteristics and influence factors of a shallow tunnel excavated in soft clay with high plasticity," Advances in Civil Engineering, vol. 2019, Article ID 7483628, 14 pages, 2019.

[6] D. Szpak and B. Tchórzewska-Cieślak, "The use of grey systems theory to analyze the water supply systems safety," Water Resources Management, vol. 33, no. 12, pp. 4141-4155, 2019.

[7] E. Javanmardi and S. Liu, "Exploring grey systems theorybased methods and applications in analyzing socio-economic systems," Sustainability, vol. 11, no. 15, pp. 3390-3395, 2019.

[8] R. C. Tsaur, "Forecasting analysis BY fuzzy grey model GM (1, 1)," Journal of the Chinese Institute of Industrial Engineers, vol. 23, no. 5, pp. 415-422, 2010.

[9] Y. Lu, Comprehensive Technology Research on Underground Mining of Primary Bauxite in Gently Inclined Thin Veins of Dafoyan, Changsha:Central South University, Changsha, China, 2012.
[10] A. Harding, M. Chappell, M. Burdick, and M. Krulc, "Opening supports to segmental linings: a novel shotcrete support solution," in Proceedings of the 15th Australasian Tunnelling Conference 2014, Sydney, Australia, September 2014.

[11] R. Das and T. N. Singh, "Effect of rock bolt support mechanism on tunnel deformation in jointed rock mass: a numerical approach," Underground Space, vol. 30, no. 3, pp. 121-127, 2020.

[12] H. Kumasaka, "Effects of distance between tunnel face and shotcrete support on support characteristic curve," Journal of Tunnel Engineering, vol. 18, no. 3, pp. 11-20, 2008.

[13] J. Y.-L. Forrest and S. Liu, "Advances in grey systems research,” Journal of Gray System, vol. 25, no. 2, pp. 1-18, 2013.

[14] Y. Zhou, Study on the Mechanical and Deformation Characteristics of the Super-large Section Loess Highway Tunnel lining, Xi'an University of Science and Technology, Xi'an, China, 2014.

[15] Y. Huo, "Comparative study on the application of gray model for forecasting tunnel surrounding rock deformation," Journal of Beijing Jiaotong University, vol. 4, pp. 42-45, 2006.

[16] J. Wu, Research on Deformation Prediction and Supporting Scheme Optimization in the Rapid Excavation of Soft Rock Tunnel, Wuhan:Wuhan University of Technology, Wuhan, China, 2003.

[17] M. Zhu, "Research on early warning technology of tunnel large deformation based on gray forecasting method," Highway Engineering, vol. 36, no. 3, pp. 83-186, 2011.

[18] Y. Chen and X. Wang, "Application of grey model in the prediction of tunnel surrounding rock deformation," Geotechnical Engineering World, vol. 12, pp. 30-32, 2007.

[19] Y. Chen, Deformation Characteristics of Weak and Broken Surrounding Rock at Tunnel Entrance and Optimization of Excavation and support, Qingdao Technological University, Qingdao, China, 2018.

[20] Y. Jia, G. Li, X. Dong, and K. He, “A novel denoising method for vibration signal of hob spindle based on EEMD and Grey theory," Measurement, vol. 169, Article ID 108490, 2020.

[21] D. Hu, K. Zhang, and J. He, "Analysis of deformation of tunnel surrounding rock based on three dimensional finite element and improved grey theory," International Journal of Earth Sciences and Engineering, vol. 9, no. 4, pp. 1839-1844, 2016.

[22] S. Sreekumar, K. C. Sharma, and R. Bhakar, "Grey system theory based net load forecasting for high renewable penetrated power systems," Technology Economics of Smart Grids Sustainable Energy, vol. 5, no. 1, 2020.

[23] Y. Lv, T. Liu, J. Ma, S. Wei, and C. Gao, "Study on settlement prediction model of deep foundation pit in sand and pebble strata based on grey theory and BP neural network," Arabian Journal Geosciences, vol. 13, no. 23, pp. 1-13, 2020.

[24] H. Li, "Grey verhulst model for tunnel deformation prediction," Journal of Shijiazhuang Railway Institute, vol. 4, pp. 28-30, 2000.

[25] S. Pan, Deformation Prediction and Numerical Analysis of Foundation Pit Excavation, Lanzhou: Lanzhou Jiaotong University, Lanzhou, China, 2018.

[26] C. Liu, W. Wu, W. Xie, and J. Zhang, "Application of a novel fractional grey prediction model with time power term to predict the electricity consumption of India and China," Chaos Solitons \& Fractals, vol. 141, Article ID 110429, 2020.

[27] X. Zhang, Research on Improved GM $(1,1)$ Load Forecasting Model Based on Numerical Analysis, Taiyuan University of Technology, Taiyuan, China, 2012. 
[28] W. Bi, G. Tian, Y. Zhang et al., "Discussion on using gray theory to predict tunnel deformation," Modern Tunnelling Technology, vol. 48, no. 6, pp. 53-57, 2011.

[29] L. Hu, Monitoring Measurement of Mountain Tunnels and Back Analysis of Surrounding Rock Parameters, Huazhong University of Science and Technology, Wuhan, China, 2016.

[30] Y. Gong and J. Zhang, "Forecast of China railway express development demand based on GM $(1,1)$ model," Scientific Journal Economics and Management Research, vol. 2, no. 5, 2020.

[31] S. Liu, Grey System Theory and its Application, Beijing: Science Press, Beijing, China, 2004.

[32] W. Wang, Research on Self-Memory Prediction Model of Foundation Pit Displacement Time Series Analysis, Central South University, Changsha, China, 2011.

[33] B. Guan, Introduction to Tunnel Mechanics, Southwest Jiaotong University Press, Chengdu, China, 1993. 